\title{
Reliability Analysis of Distribution Network Based on Reliability Index Assessment Method, A Case Study
}

\author{
Putri Zuliani, Abraham Lomi, Member IEEE, and Eko Nurcahyo
}

\begin{abstract}
A primary requirement of a modern electric power system is reasonable ability to satisfy the customer load requirements. Electric utilities involve generation, transmission, and distribution facilities each one of which contributes its own inherent difficulties to the problem of satisfying customer requirement. A power system should be designed and expanded the facilities in order to perform its intended function with a reasonable risk. With increasing the electrical energy demand and the potential of disruption that may occur in the system, the distribution system must have high reliability and continues supply to customer. In this case, the reliability of the distribution system needs to be evaluated by monitoring and analyzing the level of distribution system failure in a certain period of time. A study on a practical distribution system with application of automatic circuit reclosers (ACRs) which plays an important role in enhancing the reliability index of system is presented. The reliability index assessment analyze the reliability index of the existing system before and after application of ACRs. From the simulation point of view, the system average interruption frequency index (SAIFI) is about $19.43 \%$ or decreased the failure frequent event from $\mathbf{1 1 . 4}$ failure/ customer.year to $\mathbf{9 . 2 5}$ failure/customer.year); while the momentary average interruption frequency index (MAIFI) has decreased from 6.72 failure/customer.year to 5.05 failure/ customer.year, or increase the reliability index of about $24.85 \%$.
\end{abstract}

Index Terms-Reliability, SAIFI, SAIDI, CAIDI, MAIFI, ASAI, AENS, ACR, PT. PLN (Persero) Palangkaraya,

\section{INTRODUCTION}

Palangkaraya City is the capital of Central Borneo which is growing fast and developing in many sectors area include the electrical distribution system. The demand of electrical energy is increased from year to year as well as the population and economic growth. The existing distribution systems do not meet the reliability and continuous supply of the electrical energy. The reliability of the distribution system is relatively low, since the frequent of outages as a result of failure event in the system very often. To determine the reliability of the distribution system it is necessary to calculate the reliability index. The reliability of the electric power system is determined by the adequacy of assessment that relates to the ability of electric system to supply electric demand and energy requirements to the end-user customers at all times.

Manuscript received March 9, 2017; revised March 23, April 7, April 18, 2017; accepted April 28, 2017.

Putri Zailani is a student of the Department of Electrical Engineering, National Institute of Technology, Malang, Indonesia.

Abraham Lomi is with the Department of Electrical Engineering,

National Institute of Technology, Malang, Indonesia.

Eko Nurcahyo is with the Department of Electrical Engineering, National Institute of Technology, Malang, Indonesia.
It takes into account scheduled and reasonably expected unscheduled outages of system elements and the security of assessment that depends on the ability of the power system to withstand sudden disturbances such as electric short circuits or nonanticipated loss of system components $[1,2]$.

A unified index for power distribution reliability has been proposed in [3]. It was introduced the combination of reliability index and AvAeT index. This index avoids inconsistencies in certain of these indices, such as increases in CAIDI when automatic sectionalizing introduced. It is adaptable to fit local condition and provide the reliability solutions most appropriate for a given system.

Many component importance indices are based on classical sensitivity analysis [4, 5]. The component importance indices based on sensitivity analysis and these are tested on a small transmission system substation including eleven components. In the method each component's importance is deduced by evaluating the relative change of system reliability when the specific component is assumed to be ideal. The load points' (feeders') expected interruption frequency and unavailability are used as system reliability measures. Hilber [6] and Bertling et al. [7] present importance indices based on the sensitivity of the component i.e., failure rate, repair time and maintenance potential with respect to the system indices SAIFI, SAIDI, CAIDI, ASAI, AENS and interruption cost.

\section{MODERN EleCtriCAl POWER SYSTEM}

The electric power system has traditionally been considered to consist of three functional zones; the generation, transmission and distribution $[1,9]$. The function of the entire system is to transfer energy from the available resources to the end consumers. At practically the same moment that the energy is converted into electric power in the generation system, the energy is consumed by the end users. The bulk electric power is typically transferred in the power transmission system over long distances, at high voltage levels, from the generator utilities to major load centers. The distribution systems continue the transfer at lower voltage levels, and deliver power to end consumers. The power system consists of various types of interconnected components such as lines, transformers and circuit breakers, to enable system function. The system is constantly subjected to failures in its interconnected components, caused by for example lightning, storms, human errors, or aging equipment. Component outages in the distribution systems account for the absolute majority of the faults that result in an interruption of supply for the end consumers [1]. However, these are generally relatively localized compared to interruptions in the transmission system. The consequences to modern society of a large interruption of supply (blackout) in the transmission 
system is considerable high. Important and vulnerable functions in the society, such as telecommunication, heating and water supply, normally only function a few hours after an interruption of supply. Local backup generators can be available for some of the critical functions in the society, but this requires an organized distribution of fuel to the affected areas.

Electrical power system equipment is designed to operate within certain parameters, therefore most of the power system equipment protected by automatic devices which disconnected the system automatically in case of experienced faults or disturbances. If some faults occurred that violates the operation limits of devices, another protection devices should take action to disconnect the equipment from the system. If the protection devices experienced failure in its operation, then will be most of or some part of the system lead to a total blackout.

\section{RELIABILITY ASSESSMENT OF POWER SYSTEM}

\section{A. Outage Model for Components}

Distribution system reliability assessment deals with the availability and quality of power supply at each customer's service entrance. Analysis of customer failure statistics show that, compared to other portions of electrical power systems, distribution system failures contribute as much as $90 \%$ towards the unavailability of supply to a load. The statistics show how important the reliability evaluation of distribution systems can be.

The basic reliability indices normally used to predict or assess the reliability of a distribution system consist of three reliability indices: (a) load point average failure rate, $\lambda$; (b) average outage duration, $r$; and (c) annual unavailability, $U$. Fig. 1 shows the two state outage model for a repairable component.

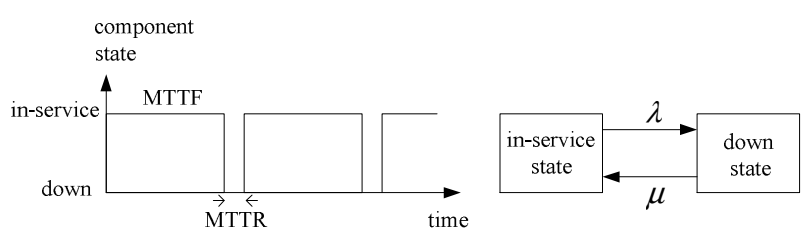

Fig.1. Two state outage model for a repairable component.

Reliability indices give a quantitative measure of the reliability indices in overall system. Calculation method uses the failure rate of each component $(\lambda)$, the mean time to fail (MTTF), the mean time to repair (MTTR), and the repair rate $(\mu)$ are described below.

Average failure rate of each component,

$$
\lambda=\frac{1}{d}=\frac{8760}{M T T F}[\mathrm{f} / \mathrm{yr}]
$$

The repair rate of each component,

$$
\mu=\frac{1}{r}=\frac{8760}{M T T R} \quad[1 / \mathrm{yr}]
$$

The average failure frequency of each component,

$$
f=\frac{1}{d+r}=\frac{8760}{M T T F+M T T R}[\mathrm{f} / \mathrm{yr}]
$$

The annual unavailability of each component,

$$
U=\frac{M T T R}{M T T F+M T T R} \quad[\mathrm{hr} . / \mathrm{yr} .]
$$

Average outage duration of each component,

$$
r=\frac{U}{\lambda}
$$

The approximate equation for the component unavailability $U$ is therefore justified in most outage types in the power system.

\section{B. System Indices Based on Load Point Indices}

In order to evaluate the severity or significance of a system outage, using three basic indices mentioned above, two expanded sets of indices listed below must also be calculated. The two expanded sets of indices include the number and average load of customers connected at each load point in the system, and the customer interruption cost. The first set is the system reliability index, which consists of:

- System Average Interruption Frequency Index (SAIFI),

- System Average Interruption Duration Index (SAIDI),

- Customer Average Interruption Duration Index (CAIDI),

- Average Service Availability Index (ASAI),

- Average Service Unavailability Index (ASUI).

In quantitative reliability analysis of power systems the main goal is to estimate the system reliability performance based on the expected component reliability. The results of the reliability evaluation are normally indices that represent the reliability of the system. Generally these reliability indices describe the system ability to supply electric energy to the load points in the system. The indices can be defined either for separate load points or for the overall system. Disturbances in the system can be categorized into sustained and temporary disturbance.

\section{DISTRIBUTION SySTEM RELIABILITY INDICES}

The distribution system reliability is usually measured in terms of several indices that are defined below. Analytical approach considered the reliability index as the sum of the contributions of individual components of failure for a year. The following equation is as a formal method for calculating the reliability index. This equation is expected to make it easier to understand. The customer oriented system indices are:

System Average Interruption Frequency Index (SAIFI),

$$
\begin{aligned}
\text { SAIFI } & =\frac{\text { Total Number of Customer Interruptions }}{\text { Total Number } \text { of Customer Served }} \\
& =\frac{\sum \lambda_{i} N_{i}}{\sum N_{i}} \quad \text { (f/cust.yr) }
\end{aligned}
$$

where $N_{i}$ is the number of customers at load point $i$.

System Average Interruption Duration Index, (SAIDI),

$$
\begin{aligned}
\text { SAIDI } & =\frac{\text { Sum of Customer Interruptions Duration }}{\text { Total Number of Customer Served }} \\
& =\frac{\sum U_{i} N_{i}}{\sum N_{i}} \quad \text { (hr./cust.yr) }
\end{aligned}
$$


Customer Average Interruption Duration Index (CAIDI),

$$
\begin{aligned}
\text { CAIDI } & =\frac{\text { Sum of Customer Interruption Durations }}{\text { Total Number of Customer Served }} \\
& =\frac{\sum U_{i} N_{i}}{\sum N_{i}} \quad \text { (hr./cust int) }
\end{aligned}
$$

\section{Average Service Availability Index (ASAI),}

$$
A S A I=\frac{N_{l p i} \cdot 8760-U_{l p i} N_{l p i}}{\sum N_{l p i} \cdot 8760}
$$

And energy oriented system indices are:

Average Energy Not Supplied per customer served (AENS),

$$
A E N S=\frac{\sum U_{l p i} L_{l p i}}{\sum N_{l p i}} \quad[\mathrm{kWh} / \mathrm{yr}, \mathrm{cust}]
$$

\section{Expected Energy Not Supplied (EENS]}

$$
E E N S=\sum U_{l p i} L_{l p i} \quad[\mathrm{kWh} / \mathrm{yr}]
$$

Where $N_{l p i}$ : number of customers in load point, lpi $L_{l p i}:$ average load demand in load point lpi.

\section{A CASE STUdy}

\section{A. IEEE-4Bus Radial System}

A radial system of IEEE-4 Bus consist of two lines each of $1 \mathrm{~km}$ length. A transformer of $6000 \mathrm{kVA}$ rated is connected between bus- 2 and bus- 3 and bus- 4 is connected to a lump load of $6000 \mathrm{kVA}$. The average failure rate $(\lambda)$ of all buses is $0.001 \mathrm{f} / \mathrm{yr}$ with the mean time of repair (MTTR) is 2 hours. The two lines have an average failure rate of 0.05 and mean time of repair of 8 hours each. The transformer average failure is $0.15 \mathrm{f} / \mathrm{yr}$ and the MTTR is 200 hours, and the lump load with $\lambda=0.02 \mathrm{f} / \mathrm{yr}$ and MTTR $=50 \mathrm{hrs}$. From the simulation results, the value of reliability indices of the IEEEbus radial system is shown in Table I.

TABLE I. RELIABILITY INDICES OF IEEE-14 BUS

\begin{tabular}{|c|cc|}
\hline Reliability Indices & \multicolumn{3}{|c|}{ Value } \\
\hline SAIFI & 0.25 & f/cust.yr \\
\hline SAIDI & 5.61 & hr/cust.yr \\
\hline CAIDI & 23.38 & hr/cust.int \\
\hline ASAI & 0.9994 & p.u \\
\hline ASUI & 0.0006 & p.u \\
\hline EENS & 30.292 & $\mathrm{MW} \mathrm{hr} / \mathrm{yr}$ \\
\hline AENS & 30.291 & $\mathrm{MW} \mathrm{hr} / \mathrm{yr}$ \\
\hline
\end{tabular}

\section{B. Palangkaraya Practical Distribution System}

Palangkaraya is the capital city of Central Borneo, which is growing and developing in many sectors. A case study of Palangkaraya $20 \mathrm{kV}$ distribution system owned and operated by PT. PLN (Persero) Central Borneo Area has been performed for simulation purposes in this paper. The $20 \mathrm{kV}$ practical distribution system of Palangkaraya is shown in Fig.1. Palangkaraya is powering by diesel power plant with total capacity of $30 \mathrm{MW}$ and the load capacity of about $45-47$ MW. It has one substation with two power transformers of 60 MVA and 30 MVA respectively and served seven feeders. The existing distribution system reliability of Palangkaraya is still relatively low. When fault occurred, a recloser is applied to protect the system and covered only feeder PRY-1, PRY3, PRY-5 and PRY-7, meanwhile the other feeders with no recloser will lead to blackout.

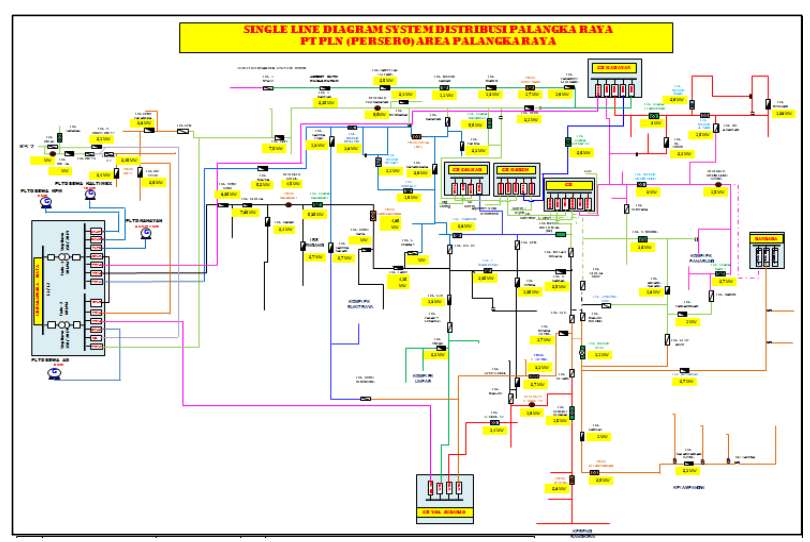

Fig.1. Palangkaraya Distribution System.

Table II shows the number of feeders experienced frequent disturbances condition per year based on the data report. It showed that feeder PRY-3 (KH-4) is the most frequent disturbances per year while feeder PRY-3 (KH-3) is secured.

Table II. The Number of Disturbances Per Feeder Per Year

\begin{tabular}{|l|c|}
\hline \multicolumn{1}{|c|}{ Feeder } & Total Disturbance \\
\hline PRY -1 & 5 \\
\hline PRY-2 & 14 \\
\hline PRY-3 (KH-1) & 26 \\
\hline PRY-3 (KH-2) & 4 \\
\hline PRY-3 (KH-3) & 1 \\
\hline PRY-3 (KH-4) & 126 \\
\hline PRY-4 & 20 \\
\hline PRY-5 & 12 \\
\hline PRY-5 (YS-1) & 5 \\
\hline PRY-5 (YS-2) & 6 \\
\hline PRY-6 & 2 \\
\hline PRY-7 & 8 \\
\hline
\end{tabular}

Based on SPLN 59, 1985 Standard [10], reliability of the existing $20 \mathrm{kV}$ practical distribution system, the failure rate and recovery time of the system are calculated. The reliability indices analysis for this practical system are focused on SAIDI, SAIFI and MAIFI. SAIDI and SAIFI for existing 20 $\mathrm{kV}$ practical distribution system of Palangkaraya were obtained by the help of ETAP software as shown in Table III.

TABLE III. RESULTS OF RELIABILITY INDEX OF SAIFI AND SAIDI

\begin{tabular}{|l|c|c|}
\hline \multicolumn{1}{|c|}{ Condition } & $\begin{array}{c}\text { SAIDI } \\
\text { (hr/cust.yr) }\end{array}$ & $\begin{array}{c}\text { SAIFI } \\
\text { (fault/cust.yr) }\end{array}$ \\
\hline PLN Standard & 12,842 & 2,415 \\
\hline Palangkaraya System & 17,7891 & 11,4878 \\
\hline
\end{tabular}

From the simulation results showed in the Table II, the reliability indices of SAIFI and SAIDI of the system were poor compared to the acceptable value based on PLN standard. To improve this reliability condition, an automatic circuit recloser (ACR) was implemented. There are five scenarios proposed in this study as follows.

Scenario-1: Feeder PRY-1 and PRY-2 installed ACRs, while feeders PRY-3 to PRY-7 are in base case.

Scenario-2: Feeder PTY-1, PRY-2, and PRY-3 are installed ACRs, include KH-1, while $\mathrm{KH}-2, \mathrm{KH}-3$ are none since of the short network and PRY-4 to PRY-7 are in base case. 
Scenario-3: Scenarios-2 and PRY-4 with ACRs, PRY-5 to PRY-7 are in base case.

Scenario-4: Scenario-3 and PRY 5 with ACRs, while PRY-6 and PRY 7 are in base case.

Scenarion-5: Scenario-4 and PRY-6 with ACRs, while PRY-7 is in base case. Beside these scenarios, ACRs are also installed on the most frequent disturbances such as PRY-2, PRY-3, and PRY-4.

The five scenario mentioned above are simulated and the results of the system average interruption frequency index and system average interruption duration index are shown in Table IV.

TABLE IV. THE OUTPUT OF RELIABILITY INDEX OF SAIDI AND SAIFI

\begin{tabular}{|l|c|c|}
\hline \multicolumn{1}{|c|}{ Condition } & $\begin{array}{c}\text { SAIDI } \\
\text { (hr/cust.yr) }\end{array}$ & $\begin{array}{c}\text { SAIFI } \\
\text { (fault/cust.yr) }\end{array}$ \\
\hline PLN Standard & 12,842 & 2,415 \\
\hline Palangkaraya Practical System & 17,7891 & 11,4878 \\
\hline Scenario-1 & 17,7411 & 11,2841 \\
\hline Scenario-2 & 17,5902 & 10,4781 \\
\hline Scenario-3 & 17,4513 & 10,3360 \\
\hline Scenario-4 & 17,2356 & 9,3266 \\
\hline Scenario-5 & 17,1548 & 9,2552 \\
\hline $\begin{array}{l}\text { Feeder with high frequency of } \\
\text { disturbance }\end{array}$ & 17,4513 & 10,3360 \\
\hline
\end{tabular}

To obtain the reliability index of MAIFI for overall system based on MAIFI calculated on each of the feeder, then summed them altogether as shown in Table V.

TABLE V. MAIFI RELIABILITY INDEX

\begin{tabular}{|l|c|}
\hline \multicolumn{1}{|c|}{ Condition } & MAIFI (fault/cust.year) \\
\hline The Existing Condition of MAIFI & 6,722995969 \\
PT. PLN Palangka Raya & \\
\hline
\end{tabular}

And the MAIFI reliability index for all the scenarios is shown in Table VI.

TABLE VI. MAIFI RELIABILITY INDICES FOR DIFFERENCES SCENARIO.

\begin{tabular}{|l|c|}
\hline \multicolumn{1}{|c|}{ Condition } & MAIFI (fault/cust.yr) \\
\hline $\begin{array}{l}\text { The Existing MAIFI of } \\
\text { Palangkaraya Practical System }\end{array}$ & 6,722995969 \\
\hline Scenario-1 & 6,540100229 \\
\hline Scenario-2 & 5,947515289 \\
\hline Scenario-3 & 5,925010883 \\
\hline Scenario-4 & 5,075458486 \\
\hline Scenario-5 & 5,048457785 \\
\hline $\begin{array}{l}\text { Feeder with high frequency of } \\
\text { disturbance }\end{array}$ & 5,098322752 \\
\hline
\end{tabular}

\section{CONCLUSIONS}

The reliability indices of the distribution system with focused on Palangkaraya practical system as a base case, the reliability indices of SAIFI and SAIDI are 11.49 fault/ customer.year and 17.79 hour/customer.year respectively. With the five scenarios strategy implemented, the most optimum value is scenario-5 with the value of SAIFI and SAIDI are 9.26 fault/customer.year and 17.16 hour/ customer.year respectively. This is shown that the reliability indices of SAIFI is improved about $19 \%$, while SAIDI is $3.54 \%$.
The MAIFI reliability index for base case is $6.72 \mathrm{fault} /$ customer.year and after installed the recloser improved to 5.05 fault/customer.year. This improvement as resulted of the installing of an automatic recloser in the bus which is frequent experienced the disturbances.

\section{REFERENCES}

[1] R. Bilinton, and R.N. Allan, "Reliability Evaluation of Power System", Plenum Press, $2^{\text {nd }}$ Ed., 1996.

[2] NERC (North America Electric Reliability Corporation). Reliability standards for the bulk electric systems of North America. Technical report, 2008. Available at: http://www.nerc.com.

[3] T. Ortmeyer, "A Unified Index for Power Distribution Reliability/Power Quality Indices,"Proceedings of 14th International Conference on Harmonics and Quality of Power - ICHQP 2010, Bergamo, 2010, pp. 16.

[4] G. Hamoud, L. Lee, J. Toneguzzo, and G. Watt. Assessment of component criticality in customer delivery systems. In Probabilistic Methods Applied to Power Systems, 2004 International Conference on, pages 819-825, September 2004.

[5] J. A. Greatbanks, D. H. Popovic, M. Begovic, A. Pregelj and T. C. Green, "On optimization for security and reliability of power systems with distributed generation," 2003 IEEE Bologna Power Tech Conference Proceedings, 2003, Vol. 1.

[6] P. Hilber, "Maintenance Optimization for Power Distribution Systems", Ph.D thesis, KTH Royal Institute of Technology, School of Electrical Engineering, Stockholm, Sweden, April 2008. TRITA-EE 2008:012

[7] L. Bertling, P. Hilber, J. Jensen, J. Setr'eus, and C.J. Wallnerstr"om. Radpow development and documentation. Technical report, Royal Institute of Tech- nology (KTH), School of Electrical Engineering, January 2008. TRITA-EE. 2007:047, Available at the publication database at: http://www.kth.se/ees

[8] Li Fangxing, "Distributed Processing of Reliability Index Assessment and Reliability-Based Network Reconfiguration in Power Distribution System", IEEE Transaction on Power System, Vol 20, No.1 February 2005 .

[9] Gunen, Turan, "Electric Power System Distribution System Engineering", United State of America: Taylor \& Francis Group, 2008.

[10] SPLN No. 59: "Keandalan 20 kV dan 6 kV", Perusahaan Umum Listrik Negara, Jakarta, 1985.

Putri Zuliani received her B. Eng. degree from Department of Electrical Engineering, National Institute of Technology in 2016. She is currently joined the Power and Energy Simulation Laboratory as an instructor.

Abraham Lomi (M'000) received Engineer degree in Electrical Power Engineering from National Institute of Technology, Malang in 1988. His Master of Engineer earned for Department of Electrical Engineering, Bandung Institute of Technology, Bandung, Indonesia and Doctor of Engineering from Energy Program, Asian Institute of Technology Thailand, in 1992 and 2000, respectively. Dr. Lomi is a Professor in Electrical Power Engineering. Currently, he is a Director of Renewable Energy Research Center and Power \& Energy Simulation Laboratory. His research area of interest include power system stability and dynamic, power electronics, power quality, renewable energy, and smart grid technology. Professor Lomi is a member of Indonesian Institute of Engineers, International Association of Engineers (UK), IEEE Smart Grid and other professional membership.

Eko Nurcahyo received Engineer degree in Electrical Engineering from National Institute of Technology, Malang, Indonesia and his Master of Engineering from the same Institute in 1999 and 2010, respectively. His research interest in electrical reliability. 